\title{
Self-video recording for the integration and assessment of generic competencies
}

\author{
Albert Masip-Álvarez, Carme Hervada-Sala, \\ Teresa Pàmies-Gómez, Antoni Arias-Pujol, \\ Carles Jaen-Fernández, Cristina Rodríguez-Sorigué, David \\ Romero-Durán, Fatiha Nejjari-Akhi-Elarab, María-Dolores \\ Álvarez-del-Castillo \\ Escola d'Enginyeria de Terrassa (EET), Universitat \\ Politècnica de Catalunya · BarcelonaTech (UPC), Campus \\ Terrassa, Spain \\ albert.masip@upc.edu
}

\author{
Marta Roca-Lefler, Jorge Hernández-Farràs, Raul \\ Montferrer-Liñan
}

Unitat de Gestió dels Serveis Comuns del campus de la UPC a Terrassa, Universitat Politècnica de Catalunya • BarcelonaTech (UPC), Campus Terrassa, Spain

\begin{abstract}
This document presents the use of a self-videorecording service for the integration and assessment of certain generic competences (oral and written communication, teamwork and third (English) language) in all degree programs related to the Industrial area at the Terrassa School of Engineering (EET). The resulting service allows to carry out the assessment through active and collaborative learning methodologies using ICT as a support, becoming an educational resource where students are encouraged to evaluate their own activity, individually and in groups (coevaluation), and with which the faculty can enhance certain sections of the syllabus while also evaluating generic competences.
\end{abstract}

This paper outlines the rationale and design of the system based on self-recording-video that assists work on some generic competences. A preliminary experience has taken place and it has been carried out by volunteer students and some professors from the promoting team. It consisted of following all steps to obtain the video-recording as a result and fulfil the further assessment. Preparing the defence of the final project career, explaining the way a problem is faced are examples of use of the service endowed to assist the assessment of some generic competences. A good number of students and professors have participated in this preliminary experiment carried out on some subjects and in which oral effective communication will be assessed. A specific rubric for the assessment of generic competences has been used both for students and faculty.

There is a summary of qualitative feedback from both students and instructors, and where several issues related to improving the self-assessment and self-video-recording system, are discussed. Finally, a survey is proposed, whose results will be helpful for its improvement.

Keywords - Video Recording, Oral and Written Competence, Teamwork Competence, English Language; Assessment

\section{INTRODUCTION}

The Technical University of Catalonia (UPC), within the framework of the European Higher Education Area, defines the generic competencies as part of the undergraduate programs. Oral and written communication, teamwork and English as a third ${ }^{1}$ language are three of the seven competencies required by UPC, which will be assessed and to be assessed at different levels of all degree programs.

Terrassa School of Engineering (EET) uses a digital platform for managing UPC studies, PRISMA, so that the specific competencies of a subject (know how) are evaluated apart from the generic competencies associated to teaching units (how to do). In order to encourage the integration of generic competences, without affecting negatively the development of the corresponding syllabuses over the academic semester, the EET provides an educational tool to assist in the developing and assessing of the generic skills of students. For that purpose, and thanks to the financial support granted by the UPC for improvement projects in teaching (Announcement 2010-2011), a room in the Terrassa Campus Library (BCT) has been set as a video recording studio. Students can book in advance a recording session by a digital platform [1] and, in this studio, they can record their own oral presentation in a completely autonomous, simple and quick way through the Adobe Connect platform. After the work is done they send the selected recorded video to the professors who will assess the corresponding competencies.

The project arose from the need to assess the generic competence "oral and written communication" together with the competencies "teamwork" and "English language" in all the degree programs related to the Industrial areas at the EET. The aim was to carry out the assessment through active and collaborative learning methodologies using information and communication technology (ICT) as a support. It turns out to be an educational resource with which students are encouraged to evaluate their own activity, individually and in

1 In Catalonia, two official languages coexist (Catalan and Spanish) and English is the main academic language. 
groups (co-evaluation), and by means of which the teacher can enhance certain sections of the syllabus while evaluating generic competencies. The video recordings, up to about 10 minutes long, capture the image from the orator and the projection of the presentation (Prezi, PowerPoint...) on a television monitor. The contents of these videos focus on solving an exercise proposed to a class group, in a way that the skills are developed and can be tested within a context. When the presentation is considered excellent, the corresponding video may become good material to be shared among classmates or to be included in latter editions of the subject. The permission of the student is required for further public use.

The development team requires of nine professors, assigned to different departments, staff from the Terrassa Campus Computer Services, Construction and Maintenance Services, and BCT. The communication channel is a wiki.

\section{AIM OF THE PROJECT}

The aim of this project is divided into two main objectives: the first is to endow the BCT with all the essential equipment needed to offer the students the possibility of recording by themselves little video presentations to be used for the partial assessment of the generic competencies along their stage at the UPC University. The main requirements for the selfvideo-recording system are:

- Autonomous booking and system for recording

- Common recording room for all the Campus students (more than 2,000 degree students)

- $\quad$ Flexible timetable

- Image and sound quality are compromised for the assessment of generic competences on the one hand, and allocation server quota, on the other.

- Video obtained immediately after the recording The second main objective is to exhort the faculty to use this assessment system using the results of a preliminary experience with.

\section{Methodology}

The project is mainly focussed on oral effective communication so that competence evaluation can be done by means of a video recording outside the room.

\section{A. Generic competences assessment and its relationship with the project}

Teaching with traditional methods that are mainly based on passing on and keeping back contents show that, nowadays, they are not effective due to the fact that knowledge is changing every day. For this reason, new undergraduate programs include generic competences, according to the framework of the European Higher Education Area. These skills should help students to reach new challenges during their professional life.

The UPC defines generic competencies as a part of undergraduate programs. These competences help students to apply their technical knowledge to their daily activity. The competences are more than knowledge and abilities. They are a complex concept because they take into account values and attitudes. The relationship between all these elements provides the students with the capacity to solve real situations in the professional and personal world. For these reasons our University encourages faculty to develop new mechanisms that guarantee competence in entrepreneurship and innovation, sustainability and social commitment, effective use of information resources, self-directed learning, efficient oral and written communication, English as a third language, and teamwork.

Nowadays, ICT offers some help to apply new learning methodologies and is a very good support for some competences. ICT can be used to access some resources and services. We can learn with ICT and through ICT. With ICT we can learn in a practical way (multimedia, digital documents, Internet, etc.). We learn through ICT because we use it as a tool/support to do our work (simulators, wikis, videos, etc.). ICT is a resource that we can include in all the different areas making class work more interactive, more autonomous, more productive, more effective and more collaborative.

For these reasons the UPC University encourages professors to develop new mechanisms to guarantee that students reach these competences when they finish their undergraduate program.

One of the competences that should be pointed out is the communication ability because it is essential to prepare presentations of projects, to discuss a proposal idea or try to solve problems some people are faced with. Good communication ability helps us to adapt our discourse in technical and not specialized environments too. If someone succeeds their specific competences are highlighted more than those of someone who has communication deficiencies. Poor communicative ability could hide our real technical knowledge.

After we decided to develop a mechanism that could help our students to increase their effective oral skills we thought that self-recording videos would be a good tool because they integrate ICT (tools to self-record their videos) and some other competences (teamwork and third language).

The experience has focused on some specific subjects. In these subjects, the entire class group is divided into subgroups of a smaller size. The professor assigns a specific job to each group of students and, at the end; each team has to hand in short video, about 5-15 minutes long, where they explain the results of their work.

To begin with, students have had to work autonomously, which implies the ability to detect gaps in their own knowledge and to overcome them through critical thought and choosing the best action to extend their knowledge. They also have to work as a team member, either as a member or performing management tasks in order to help develop projects pragmatically and responsibly, taking commitments considering the available resources. Those abilities are assessed following table I. 
TABLE I. RUBRIC FOR WORKING IN GROUPS

\begin{tabular}{|c|c|c|c|c|}
\hline & \multicolumn{4}{|c|}{ Qualification } \\
\hline & $\begin{array}{c}\text { Insufficient } \\
\text { (1) }\end{array}$ & Acceptable (2) & $\begin{array}{l}\text { Outstanding } \\
\text { (3) }\end{array}$ & $\begin{array}{c}\text { Excellent } \\
(4)\end{array}$ \\
\hline $\begin{array}{c}\text { Contributions } \\
\text { to team }\end{array}$ & $\begin{array}{c}\text { Just a part of } \\
\text { the team has } \\
\text { worked }\end{array}$ & $\begin{array}{l}\text { Almost all have } \\
\text { been involved + } \\
\text { have completed } \\
\text { their work }\end{array}$ & $\begin{array}{l}\text { All have } \\
\text { contributed } \\
\text { to the team }\end{array}$ & $\begin{array}{l}\text { All the team } \\
\text { has been } \\
\text { involved in } \\
\text { similar tasks }\end{array}$ \\
\hline Sharing & $\begin{array}{l}\text { There have } \\
\text { been some } \\
\text { conflicts in } \\
\text { team } \\
\text { discussions }\end{array}$ & $\begin{array}{l}\text { There have } \\
\text { been no } \\
\text { conflicts but not } \\
\text { everyone } \\
\text { participated } \\
\text { equally }\end{array}$ & $\begin{array}{c}\text { Sharing has } \\
\text { helped plan } \\
\text { and answer } \\
\text { questions }\end{array}$ & $\begin{array}{c}\text { Discussions } \\
\text { adjusted for } \\
\text { group } \\
\text { cohesion } \\
\text { and } \\
\text { teamwork }\end{array}$ \\
\hline Autonomy & $\begin{array}{l}\text { There was } \\
\text { still need for } \\
\text { teacher }\end{array}$ & $\begin{array}{l}\text { There is rarely a } \\
\text { need for } \\
\text { teacher's help }\end{array}$ & $\begin{array}{l}\text { The team } \\
\text { often solved } \\
\text { the problems } \\
\text { themselves }\end{array}$ & $\begin{array}{l}\text { Problems } \\
\text { discussed in } \\
\text { groups and } \\
\text { find } \\
\text { solutions }\end{array}$ \\
\hline
\end{tabular}

Because the video is used in this project as a means to enhance student capabilities to communicate, one of the goals is for video to become a powerful tool for improving communication. Students are able to watch themselves, and therefore, repeat the recording until they are satisfied. On the other hand, the professor can evaluate the communication skills of students. The scoring rubric used to evaluate this ability is shown in table II.

Over all these items, some of the presentations can be done in English, which might be an added value to students' curriculum.

TABLE II. RUBRIC FOR ORAL COMMUNICATION

\begin{tabular}{|c|c|c|c|c|}
\hline & \multicolumn{4}{|c|}{ Qualification } \\
\hline & $\begin{array}{l}\text { Insufficient } \\
\text { (1) }\end{array}$ & $\begin{array}{c}\text { Acceptable } \\
\text { (2) }\end{array}$ & $\begin{array}{l}\text { Outstanding } \\
\text { (3) }\end{array}$ & Excellent (4) \\
\hline Contents & $\begin{array}{l}\text { Simplistic } \\
\text { ideas }\end{array}$ & $\begin{array}{l}\text { Correct but } \\
\text { incomplete }\end{array}$ & $\begin{array}{l}\text { Covered all } \\
\text { topics }\end{array}$ & $\begin{array}{l}\text { Explored the } \\
\text { issues }\end{array}$ \\
\hline $\begin{array}{l}\text { Organization of } \\
\text { content }\end{array}$ & $\begin{array}{c}\text { Poorly } \\
\text { structured and } \\
\text { difficult to } \\
\text { understand }\end{array}$ & $\begin{array}{c}\text { Sequencing } \\
\text { correct but } \\
\text { sections are } \\
\text { isolated }\end{array}$ & $\begin{array}{l}\text { Have tried to } \\
\text { relate the } \\
\text { various } \\
\text { explanations }\end{array}$ & $\begin{array}{c}\text { Different } \\
\text { sections } \\
\text { planned for } \\
\text { an overview }\end{array}$ \\
\hline Communication & $\begin{array}{l}\text { Unclear. } \\
\text { Hard to } \\
\text { follow }\end{array}$ & $\begin{array}{l}\text { Clear and } \\
\text { comprehens } \\
\text { ible in } \\
\text { general }\end{array}$ & $\begin{array}{l}\text { Fluent. The } \\
\text { audience } \\
\text { follows with } \\
\text { interest }\end{array}$ & $\begin{array}{l}\text { Appropriate } \\
\text { tone and } \\
\text { precise } \\
\text { language. }\end{array}$ \\
\hline $\begin{array}{l}\text { Audiovisual } \\
\text { support }\end{array}$ & $\begin{array}{l}\text { Little and } \\
\text { highly } \\
\text { inaccurate }\end{array}$ & $\begin{array}{c}\text { Suitable } \\
\text { although } \\
\text { not } \\
\text { thoroughly } \\
\text { developed }\end{array}$ & $\begin{array}{l}\text { Appropriate. } \\
\text { Helped to } \\
\text { understand the } \\
\text { concepts }\end{array}$ & $\begin{array}{c}\text { Very } \\
\text { interesting } \\
\text { and engaging. } \\
\text { They have } \\
\text { been an } \\
\text { excellent } \\
\text { support for } \\
\text { each other }\end{array}$ \\
\hline Teamwork & $\begin{array}{c}\text { Too } \\
\text { individualistic }\end{array}$ & $\begin{array}{l}\text { Presentation } \\
\text { shows some } \\
\text { planning }\end{array}$ & $\begin{array}{l}\text { All members } \\
\text { know the } \\
\text { overall } \\
\text { presentation }\end{array}$ & $\begin{array}{c}\text { Planning and } \\
\text { team work are } \\
\text { shown }\end{array}$ \\
\hline
\end{tabular}

\section{B. ICT background}

Some different ICT tools have been considered before deciding a way to proceed; two of them are offered by our University. Below there is a list of the analysed ICT we found useful for our needs:
a)PRESENT@ [2]: An environment, developed within the Universitat Oberta de Catalunya, by means of which students and faculty can upload videos, being able to provide a description, assign the corresponding license or apply a category. This resource implies, by and large, that students or faculty can record their speech by themselves while the explanation of some topic is being carried out; absolutely no image of the orator is shown on the screen, only the sequence of shots of the presentation appears. Camtasia software tool can be used for this aim.

Its main new development with regard to other tools is the possibility to comment on videos, both for students and professors, which can lead to a range of discussions, all integrated in the same space. This project was funded by AGAUR [3] in 2010 and received an award for being an innovative project in 2010.

b) MEDIATIC [4]: A project that offers tools for creation, indexation, publication and broadcasting of audiovisual resources. The main objective is to contribute to better quality teaching at the University and to improve learning process by means of short audiovisual pieces. It is addressed mainly to faculty. As a result, video lessons about some subjects are obtained. They are indexed and further published to students through a web portal. These video explanations are between 5-10 minutes long and they reinforce some difficult issues related to the contents of a subject, help with key concepts of subjects difficult to learn, with solving an exercise, or provide video demonstrations about software tools. Their aim is not the assessment of generic competencies in the orator. The resulting videos are made up of two frames: both slides of the presentation and the orator carrying it out can be seen. They offer a high image resolution of the slides and they also allow watching the orator standing next to them. This service needs some personal assistance and it is not possible to carry it out in an autonomous way. All recordings need to be edited in postproduction by technical staff. Booking of recording sessions is managed by means of a booking software tool.

c) SELF-VIDEO RECORDING SERVICE [5]: Video recording, edition and storage resources are barely offered at different libraries at the UPC. As a unique example, Baix Llobregat Campus Library is endowed with all the necessary resources for the recording and further edition of videos. The aim of these videos is to improve teaching by means of technical innovation; all the recorded videos deal with subjects related to science and technology.

This service is offered to faculty with the aim of helping with their lectures and also to students that need to record some materials related to any subject; it offers the recording of a teaching "pill”. The time interval between the recording and the availability of the video may vary depending on the load of work the library staff; this is due to the need of postproduction work.

When necessary, some assistant staff from the library will help the orator with the recording, although it is a selfvideo-recording service. The recording studio is open about seven hours and a half per day. It is designed in a way that 
the orator and the material (slides, presentation) can be recorded simultaneously but, when desired, only the lecturer is shown. Camtasia Studio software is used in this environment. Two people are needed when a recording is being done: one is the orator and the other one is supporting him with the computer. A CD-ROM, DVD or USB memory pen-drive is necessary to get the recorded video; the file can also be sent by e-mail or shared in the cloud.

The closest ICT tool to our interest is the latter one; but the specifications for this project are slightly different: the system must be absolutely autonomous, with a wide timetable for its use and the use of Adobe Connect is mandatory. The reason is that it is a wager for cohesion with all the video and web-conferences that are taking place in the Campus of Terrassa of the UPC, to which the EET belongs. It is a standard and common ICT tool that is widely supported, and Terrassa Campus Computer Services (SICT) has experienced with it extensively. But to balance all the considered specifications and actions, the large number of members in the team needs to be closely coordinated.

\section{Group members coordination}

The development team is made of nine professors, assigned to different departments, staff from the SICT, Construction and Maintenance Services (SOM), and BCT. During the process in which we carried out the creation of the self-recording room we had to make some decisions about what equipment we could use to make the most of it and obtain the best results. Thus, this way the first important decision was: what do we want to assess in the videos? The Wiki [6] (PbWorks) was chosen as an efficient platform for discussing and selecting the options that the members of the team would have. The use of ICT like wikis improves the efficiency of the project and if we think that it is a good tool for our students it should also be good for us in order to minimize the on-site meetings. Through this platform group members have made technical and methodological choices about the image angle, the length of the video recordings, their destination, the rubrics and student satisfaction surveys, etc. So the wiki is organized into different sections: staff, technical decisions to take, calendar, work plan and meetings, as shown in Fig. 1.

\section{Specifications}

The options to select from were:

- Framing: medium/American/ general shot. We want to see how the students use body communication in their speech. - Maximum duration of the video recording: 8 "or 10". It should be enough to assess the student's work. - The students will use the projected image on the wall / screen by means of a beamer, they will use the projected image on a TV monitor or they will use the beamer image projected on a whiteboard.

To help the team choose the best option, a record of all the cases previously mentioned was accessible in the WIKI. Professors were asked to choose the best and less expensive option that would identify the key elements that characterize the oral presentations of the students. A self-recording that would last for 10 minutes in a general framework using a projected image on a TV monitor would be the best option. First we decided to go for a general shot but after some more tests we saw that the American shot was enough and that it improved the presentation image.

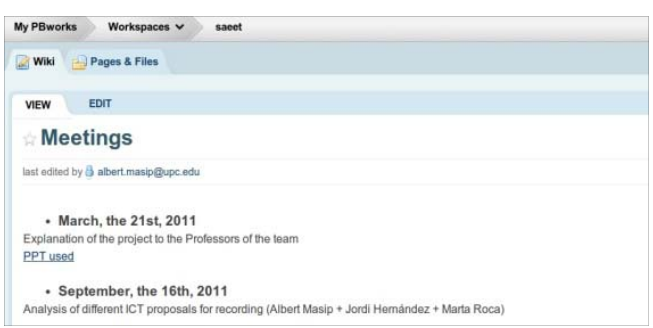

Figure 1. Meetings section of PbWorks wiki for the project

For the team involved in this project, and especially the professors, the evaluation of the oral competence through students' presentations was very important. However, in this case the objective was to assess the use of body communication instead of presentation contents (PowerPoint, Prezi...). Hence our biggest effort was to have the best sound quality and the best image of the student. Figure 2 shows the layout of the self-recording room with the main elements: a camera, an ambient microphone, a screen and the computer in order to control the whole work session. The dotted area is the zone captured by the camera.

Thus, we decide the shot (General, American, ...) that it will show us what we want to assess. In the end we decided to use medium shot because it shows body communication and the presentation document on the TV screen. The professor can see how the explanation is related to the presentation, and presentation contents can be seen quite clearly. However, this is less important because the final work and presentation are also sent to the professor. Furthermore, we configured three set-ups: one for lefthanded people, another one for right-handed people and a third one with which the student can use both sides of the screen during the presentation. This set-up is selected by the student when the session starts. Figure 4 shows a left-handed set-up in a real self-recording.

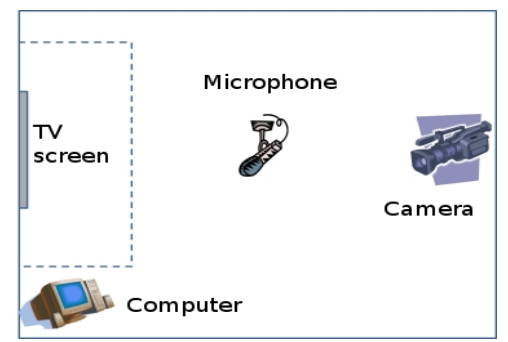

Figure 2. Layout of the self-video recording room

Another special set-up is related to the sound captured because if the student is turned to the screen and s/he turns his back to the audience, the voice is penalized. This is a way to encourage students talk clearly to the audience. The last important decision for the final room set-up was the screen to show the presentation. In our case the self-recording room is 
not big enough if we want to use a projector. It's for this special situation that we decided to install a flat TV screen to improve the final view of the recordings. Moreover, a TV is better than a beamer because artificial light from lamps can be used to illuminate the figure of the orator.

\section{E. ICT architecture}

The ICT requirements for the assessment of oral communication capabilities are aimed at the simultaneous recording of image and sound while the student is doing a presentation. Audio quality is considered that it is no necessary to obtain a high quality image caption for the correct assessment of the generic competence. For that reason, video quality is not the priority, nor is the quality of the presentation shown on the TV screen. The standard quality obtained for the resulting video is an important fact when optimising server resources. Small size video files are obtained.

The computing tool for managing videos and the booking of virtual rooms is developed by SICT and it is based in Mr BOSY from Universidad Carlos III (Madrid). Figure 3 shows the functional scheme of all the hardware and software elements involved.

It turns around three main servers: one is the Adobe Connect server itself; the other is the LDAP server for the authentication of users as UPC members and finally the Apache server for the virtual rooms. The latter is the one which the user has to connect with via HTML for the supplying of the web pages for the resource. PHP channel allows providing different resources to Adobe Connect: the generation of a database for the users and their privileges for managing registered videos, SQL queries for session parameters and generated files...

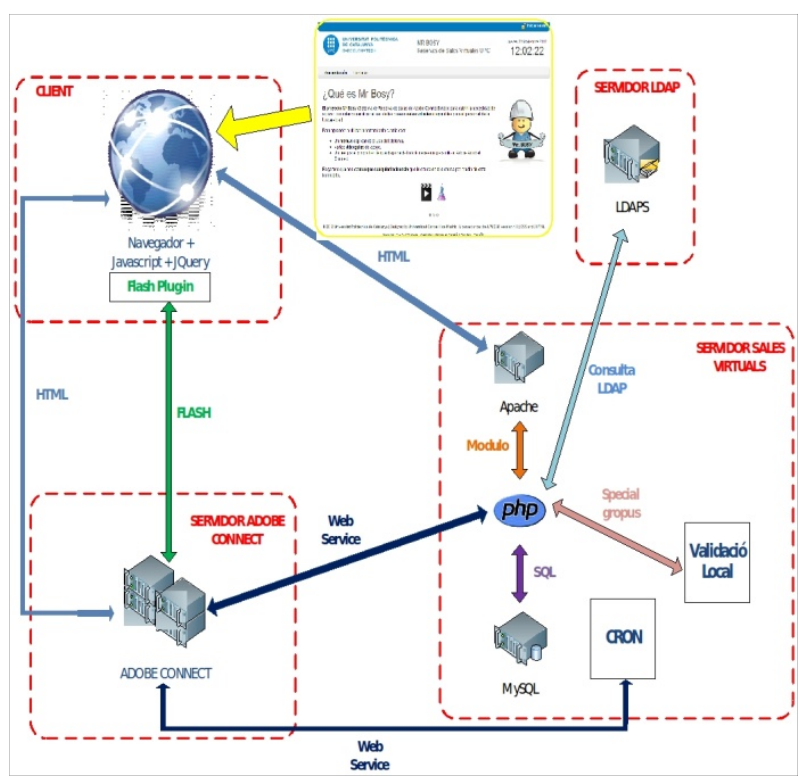

Figure 3. Schematic map of all ICT elements involved in the selfvideo-recording project

\section{PROCEDURE}

The first step of the activity is the professor sending the list of students that will perform the task to an e-mail address. The sent file is a CSV-type and it only contains the e-mail address and the name of the student. If the task must be done in groups, the file contains only information about the student responsible in each team. Next, the professor defines a workshop in ATENEA, the Moodle based platform for managing courses in the UPC. The explanation of the solution adopted is done by means of a presentation in the self-video-recording studio. The assessment of oral effective communication, teamwork, and English as a third language, can be done through co-assessment, self-assessment and assessment by the professor, in a combined way.

Students are informed to book the self-videorecording room in advance; every student can book only the room three times per subject in order not to overbook this resource. They are warned that one hour is not long enough if they are not coordinated and if they have not rehearsed the oral presentation before. Students can cancel their bookings if they are not able to use the resource; if it is not cancelled, one of each three bookings is lost. If only one hour is not enough, students can book the next hour if it's not occupied. Booking can be done within the room. Students can repeat recordings while they are using this service and finally select the video to be sent to the professor for the assessment of the generic competence. The maximum recommended video length is about ten minutes. The recorded videos can be watched during the semester they are recorded in. At the beginning of the next semester they are all deleted in order to manage server quota, except those videos which are interesting to keep as teaching material or as examples of good practice.

There is an extensive manual [9] describing the whole process but it is summarised in only one sheet that can be found in the room itself. When the recording is finished and the student has decided which video is the chosen one, the URL for the file is obtained. The video needs to be defined as public so the other people can watch it afterwards. The URL of the recorded video must be sent through the workshop (Moodle) for the assessment of some generic competences and also the final work and presentation must be sent to the professor for the evaluation of specific competences.

\section{RESULTS}

About three dozens of students have used the equipment between May the 1st and November the 23rd within a preliminary experiment whose outcome will lead to a more extensive experiment. When asked, they find this service really useful, as do professors. But there have been some technical that it will be solved in due course: audio connectors are too accessible so someone could disconnect them; sound and image configuration steps for Adobe Connect are so rigidly ordered that is so easy to skip some. But the resulting videos in this preliminary experiment are good enough for the assessment of the generic competences treated along this article. A single shot of a recorded video can be seen in figure 4 . It shows a student explaining the 
solving of a problem defined in a workshop. Nevertheless, the resource has also been used for preparing the defence of a final career project by some students.

Two different surveys are designed in order to assess the use of these self-video-recording systems both for the students [10] and for professors involved in the evaluation process skills. We are now in a preliminary stage in the assessment of this resource so the results of the survey must be taken carefully. Not enough students have used this resource to take into account statistics derived from the survey. So the results of these works are mainly qualitative. The results show that the instructions given to students to reserve the room, record video and send the resulting video have been easy and understandable. However, there is a need to improve the instructions located in the recording room, as well as technical aspects such as the use of the pin slides that have caused some problems, as some users have made some comments accompanying the survey. In general, users are very satisfied with the recording room, in regard to the level of silence or the air conditioning. The level of satisfaction of the schedule has been slightly lower possibly because the last few days before the delivery, the schedule recordings available were less than desirable. The satisfaction level of students regarding the resulting video, as well as the degree of achievement or improvement of oral skill is very high. Recording the video and then watching it to see some errors while carrying out the presentation, makes it possible to improve the final product.

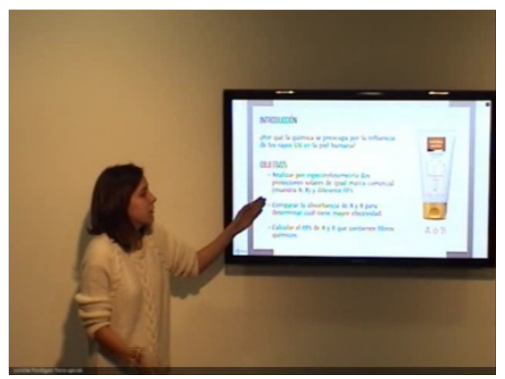

Figure 4. Shot of a standard video recording resulting from the project

Feedback from teachers has been very positive in terms of time saving achieved compared to the methods used previously, because evaluating the competence of oral communication through videos of teaching hours devoted to the subject but it served to reinforce certain aspects of the syllabus. Also have a positive skills assessment and they have seen most motivated students by the use of the new method, but have seen some aspects that can be improved in the future regarding the instructions given to students.

\section{CONCLUSION}

It has been developed a self-recording service in a specific room at the BCT. As expected, the impact on academic achievement has been very positive. The service has implemented several improvements including the use of video, recording groups of students rather than individuals, and the addition of a peer review activity for students to view the videos together and exchange comments by using Moodle-based platform.

The self video recording and later viewing of videos offers the opportunity to show the integration of certain generic competences into the undergraduate courses in a virtual environment. It is a resource which motivates and conveys information and, at the same time, it becomes a teaching tool appropriate for fostering generic competences.

The key points of this resulting service are: immediacy in obtaining video, no further edition required, common place (library) in the Campus where work presentations are done, wide timetable available at the library (ten hours per day), no additional staff required (neither for recording, nor for editing), no time wasted in doing presentations at in-site lectures in the classroom, generic competence assessment (oral efficient communication, teamwork and English as a third language), and co-assessment and self-assessment can be also done by means of a digital platform as Moodle.

A preliminary experiment has been carried out and it will lead to a more extensive experiment. When asked, both students and faculty find this service really useful. But there have been some technical problems that will be corrected in due course. One of the possibilities to explore is to minimize the complexity of the ITC system in order to simplify the software tools involved in this project.

\section{ACKNOWLEDGMENT}

The authors wish to acknowledge BCT, SICT and SOM for their aid and support provided throughout the project. This project has been carried out thanks to the grant provided by the Education Science Institute (ICE) of the UPC.

\section{REFERENCES}

[1] http://bit.ly/XyYy2K

[2] Pérez-Navarro, A.; Conesa, J.; Valls, A. Presenta@: an environment for virtual dissertations in final degree projects. EDULEARN12 Proceedings, pp. 2384-2393.

[3] Catalan Agency of Grants for University and Research

[4] http://mediatic.upc.edu/

[5] http://bit.ly/XyYy2K

[6] http://saeet.pbworks.com

[7] https://atenea.upc.edu/moodle/

[8] http://red5.upc.es/autoenregistrament/

[9] http://bit.ly/Vmwz7P

[10] http://bit.ly/Tw5MnA

[11] Cazcarro Castellano, I.; Martínez Caraballo, N. "La grabación en vídeo en el aula como herramienta de mejora de la competencia de comunicacion oral,” Educatio siglo XXI. vol. 29, num. 2, pp. 255 282, 2011. Available: <http://bit.ly/XyYDDk>

[12] Christianson, M., \& Hoskins, C. (2008). Designing a program-wide self-assessment system for academic speaking: Preliminary results and issues. The ICU Language Research Bulletin, 23. Available http://web.icu.ac.jp/lrb/vol_23_files/Christianson\%26Hoskins2.pdf.

[13] Mort, Jane R.; Hansen, Daniel J. Self-Assessment of Communication Skills and the Impact of Video Review. Am J Pharm Educ. 2010 June , vol. 74, num. 15, pp. 78. Available: < http://1.usa.gov/YpzdyL >

[14] 5 Effects of a Self-instruction Communication Skills Training on Skills, Self-efficacy, Motivation, and Transfer. Available http://www.eurodl.org/?article $=470$ 